\title{
Quality Systems at Universities in Academics' Perception: A Systematic Literature Review
}

\begin{abstract}
Agnieszka Lęgocka*
\section{Summary}

New public management, as well as institutional and market pressure, brought business-like requirements to HEIs. Their implementation resulted in profound changes in university governance. This paper presents a systematic literature review of the scholars' perception of a quality system introduced by new public management and the corporatization of universities. The implications of the new practices and discourses for academic identity, university governance, power-balance, as well as the role of a scholar are investigated. The findings reveal that the underlying values and university culture stay in tension with managerialist ideology. The presence of the institutional logics approach in a university context was also examined. It enabled to analyze whether it was used in the context of providing insight into the academics' perception of quality assurance systems.
\end{abstract}

Keywords: Institutional logics, University governance, Quality systems

JEL: Classification: M14

\section{INTRODUCTION}

Policies and regulations on both, the national and supranational level, are designed to build a knowledge society and to bring more transparency, accountability and legitimacy into the university. The provision of various legal requirements is a sign of changing and raising expectations of governments and society towards universities in recent decades. They had to transform from a republic of scholars delivering independent thought and educating elites, to providers of ready-touse knowledge and skills for a high percentage of the population. In addition, they had to conduct research of tangible practical application within a shorter timetable and for short-term profits, as well as to cooperate with external stakeholders in ways and to the degree of which they never experienced before. New ways of financing these institutions were introduced. The pressure of accountability and value for money was increased, which lead to the reduction of stable state financing in place of grants for which one has to compete for. Those transformations lead to profound changes in terms of the role and identity of a university and entail rethinking its mission, strategy, functions, structure and objectives. Those expectations and legal requirements that the university needed to fulfill resulted in, among others, developing and implementing internal quality assurance systems.

It may be argued that such systems in principle should advance the quality culture in the organization, enable to deliver valuable information for the stakeholders - especially academic teachers and University authorities - of the current state of art of the quality of teaching and research; therefore become a crucial instrument for organization's self-improvement. However, it may be questioned whether that is the case. What exactly does quality mean? How the definition of quality can be actually an arena of political struggle? What is the impact of quality systems on crucial agents participating in its inception and development? What is the opportunity cost that these agents pay for their involvement in the system? What is there to gain on the university level,

\footnotetext{
Faculty of Management, University of Warsaw, Poland, https://orcid.org/0000-0002-5501-9767, e-mail: ALegocka@ wz.uw.edu.pl
} 
faculty level, and personal level? Who (if anyone) and why is interested in the actual evaluation of the quality system and its improvement?

As the quality assurance system is to deliver more data on performance and level of excellence in teaching and research, one may ask: is it used, and if so - how, in order to benefit university governance? Is it perceived as a useful tool, or rather an obstacle generating a lot of unnecessary workload and documents? Where to place quality systems on a landscape that has university autonomy on an operational and strategic level on the one end, and subordination to the state through established policies and goals on the other? Finally, in the light of that dichotomy, how do the agents provide meaning, values and rationality to their actions concerning quality systems?

This paper aims of to investigate to what extent answers to the questions listed above were already provided and to draw conclusions on what is currently known about the topic. Therefore the analysis of 58 papers on quality assurance, university governance and institutional logics is presented. In particular, I will be looking for those theoretical approaches and research findings that broaden the knowledge of academics' motivation towards participation in quality assurance activities and their understanding of its meaning and goals. The three focal issues investigated in the paper are quality assurance, university governance and institutional logics.

I acknowledge the Stensaker (2007) stance that regards the notion of quality assurance as fulfilling the requirement for being considered as a Wittgenstein's notion of "a family of meaning". The concept of quality assurance used in HEIs, having a variety of overlapping similarities, escapes the attempts to capture all of them in a definition. Therefore, it is treated in this paper as a natural, fuzzy concept and no attempt to define it is made.

The definition of university governance adopted for the paper is the one proposed Shattock (2006): "Governance is defined as the constitutional forms and processes through which universities govern their affairs.(...) extending right through the institution from a governing body, down through senates and academic boards to faculty boards and departmental meetings and it regards governance as being effective when these levels of governance work together productively" (Shattock, 2006, p. 1). When we treat teaching and research as core activities of universities, "we have to believe that the organs of governance which coordinate, incentivize and sometimes direct these activities carry equal weight in the governance of the institution as a whole even if they may not have the final decision on the fundamental strategic and financial issues. This might lead us to see the university governance, not from the top of the basis of who governs who, but part of the organizational law of the institution"(Shattock, 2006, p. 1).

The decision of encompassing university governance was undertaken to enable including a wider perspective of the current paradigm shift in university governance modes. Firstly, that may be very valuable for interpreting the academics' views on quality systems regarding a broader spectrum of current changes, one of which is university governance. Secondly, quality systems are frequently interpreted as a part of a new mode of governance. Therefore it was purposeful to investigate whether there is any research concerning the relation between the perception of governance and quality systems. The institutional logics perspective is one of the analytical approaches that enable one to capture and interpret clashes and tensions between a set of interlinked values, beliefs, rules and assumptions - a broader belief system (logic) providing explanations for the sense-making and actions of people. The paper investigates whether this analytical approach has been used in the context of quality assurance systems at universities, provided that there may be some collisions of logics.

To foster future research and contribute to the insight into current knowledge, the paper was structured as follows. The research method is explained, keyword string is specified, and the eligibility, as well as exclusion criteria, are given. Having presented the general overview of 
the evolvement of the research issue through time, the 58 selected papers that met the criteria are introduced and studied. On the basis of this analysis, the articles are organised into 4 major strands: quality assurance, academic values, university governance and institutional logics. Some of the main topics are divided into subtopics, when cogent. Summary of the findings embracing all strands show that quality a) along with the new managerialism leads to undermining traditional academic values b) is seen as a form of, mistrust and regulatory tool with limited (if any) interest of academics and impact on core academic activities c) is one of the factors leading to substitution of academics' participation in governance by various coping strategies. Subsequently, the contribution of the paper in terms of identifying knowledge gap is presented. The conclusion is drawn that employing institutional logics perspective to analyse quality assurance systems' perception is a research gap. On account of a small number of quantitative studies, longitudinal studies and cross-country comparisons, the need for employing a wider range of research method than qualitative ones is also recognised. The concluding section presents the limitation of the paper.

\section{RESEARCH METHODS}

The systematic literature review methodology applied in this paper follows the procedure proposed by Briner and Denyer (2012). The review methodology began from searching the following keywords representing three components of the research problem: a) internal assurance or internal system(s) and university/universities, b) institutional logic, and c) university governance. The search in the SCOPUS database revealed that there are no papers which would employ both analytical frameworks to quality assurance systems. What is more, there are no papers that would employ only institutional logics to quality assurance systems. Therefore, it seems that those theoretical approaches have not been jointly applied to quality assurance systems, which provides an interesting research gap to explore.

The query used in the SCOPUS database was the following: "institutional logic*" OR "university governance" OR "quality assurance" AND Universit* AND NOT "health care" AND NOT "product development". The phrase Universit* was added to narrow the number of records concerning quality and to receive the most relevant ones. Since a number of the records received was connected with health care and product development, the query was modified to exclude them. This research returned 4,323 documents.

The search was then restricted to

- "Subject Area": Business, management and accounting", "Social sciences" and "Economics, econometrics and finance";

- "document type": "Article" and "Article in press";

- "Source type": "Journals";

- "Language": "English".

That limited the number of records to 1346 . No restriction on the search regarding time limit was put.

\section{OVERVIEW OF THE RECORDS}

The earliest paper was from 1973. Until 1992 up to two papers a year were published, and since 1993 the number of papers started to rise to reach 136 in 2017. The papers published between 1973 and 1992 were covering such topics as quality assurance in various fields, and university governance. After Friedland and Alford (1991) publication on institutional logics followed. The first paper that links quality assurance systems with autonomy is from 1993 and states that "if university autonomy 
is essential for the proper functioning of universities, then quality control and management are essential prerequisites for autonomy." (Berg, 1993, p. 18).

Three of the papers identified by the keywords present a systematic literature review. One concentrates on the literature on university governance published in the United States between 1970 and 1990 (Ordorika, 2014). Said paper arranges the articles into four analytical perspectives (organizational/functional, organizational/interpretative, societal/functional and societal/interpretative). It argues that all of the existing theories are insufficient, especially in terms of understanding the change in higher education institutions and in the position and role of the state (Ordorika, 2014). The second systematic literature review provides a comparison of theoretical models of academic governance in the context of Connell's Southern theory by indicating differences and similarities between the US, England and Australia (Rowlands, Ngo, 2018). The third one provides a bibliometric analysis of papers concerning quality assurance for concluding that quality assurance of teaching and learning is becoming a speciality in the interdisciplinary field of higher education research (Steinhardt et al., 2017). No SLR concerning quality assurance was found.

\section{ELIGIBILITY CRITERIA}

The 1346 papers were read and evaluated according to the criteria presented below. That process enabled to select only those papers that will allow to gain more insight into the research questions and therefore were evaluated as relevant. The final number of papers decreased to 58 .

During the selection process the following criteria were adopted:

The paper covers

1. Quality assurance systems or some of their aspects in the light of academics' perception and assessment of it;

2. The impact of quality assurance system on the academics regarding their career development and roles played at the university;

3. The conflict of motivations, roles and expectations that the academics face, especially concerning quality assurance systems and/or university governance;

4. The meaning, value and associations that the academics have towards quality assurance systems;

5. The present conflicting or competing requirements concerning various aspects of university functioning on the personal and/or university or state level.

Therefore, the papers covering the following topics were excluded:

1. The other stakeholders view such as students, and social and business partners on quality assurance system or/and university governance;

2. The comparison of various university governance and quality assurance systems models;

3. The measurements of the effectiveness of specific quality solutions at universities, for example distant learning.

\section{FINDINGS}

The further presentation of the analysis of the findings is structured around four main themes that were the result of thematic analysis performed: quality assurance, governance, institutional logics and academic values. Additional subtopics appear if justified. The conclusions drawn together from the analysis of these three sections are presented afterwards. 


\section{OVERVIEW OF THE SELECTED PAPERS}

The figure presenting the distribution of the selected papers over time is presented.

Fig. 1. The distribution of papers selected for the SLR over time.

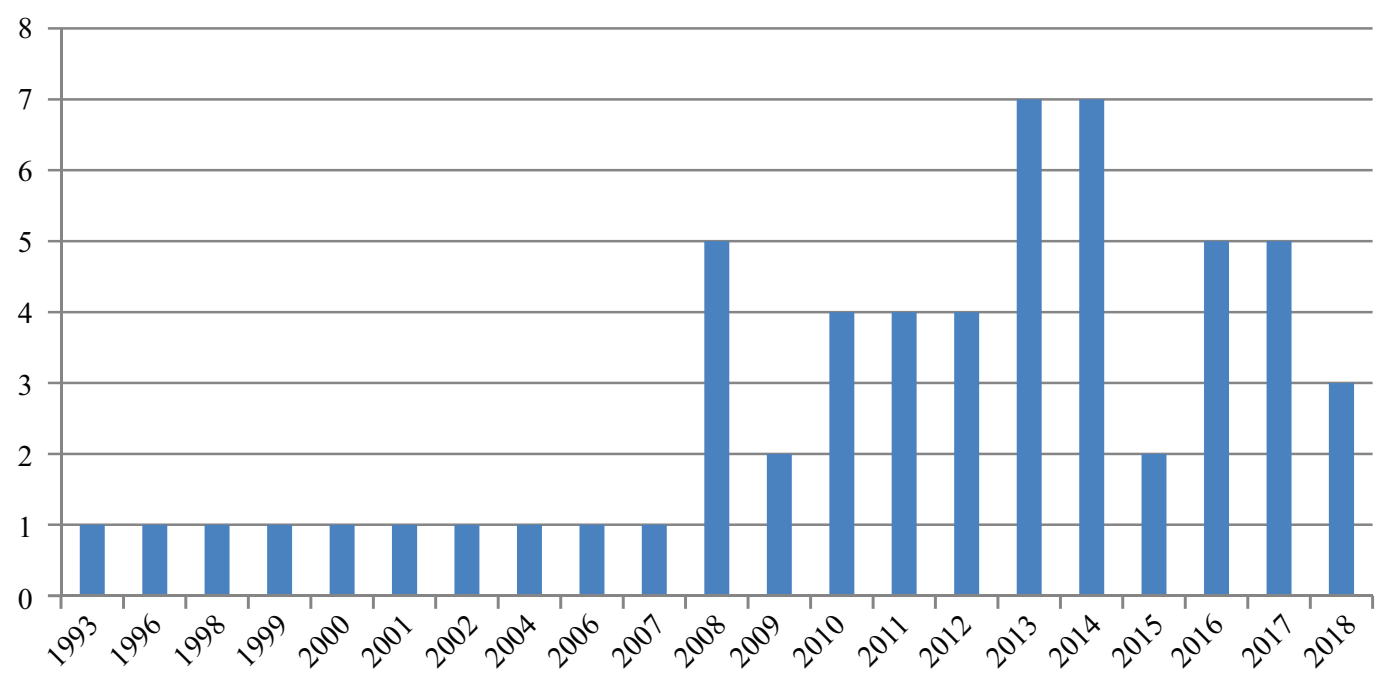

The list of journals with the number of papers included in the SLR are presented in the attachment.

Below the table presenting the analytical method used in empirical papers is presented. Out of 58 selected articles, 14 are conceptual, with no empirical data. Majority of the rest (39) is qualitative. Sample sizes vary - from 5 to 135; however, most of the samples consist of 20 to 50 interviewees. There are only 8 papers that employ a quantitative approach. Three papers use both qualitative, and quantitative method, so the count data are not mutually exclusive.

Table 1. Analytical method used in empirical papers

\begin{tabular}{lc}
\hline \multicolumn{1}{c}{ Method } & Number of Times used \\
\hline Qualitative & 39 \\
(case studies, interview analysis, content analysis, secondary data analysis) & 8 \\
Quantitative & 2 \\
descriptive statistics & 1 \\
t-test & 1 \\
factor analysis & 1 \\
SEM & 1 \\
hierarchical cluster analysis & 1 \\
GEE regression & 1 \\
non-parametric statistical tests & 1 \\
\hline
\end{tabular}

Note: of the 58 papers, 14 are conceptual. 


\section{QUALITY ASSURANCE}

Among the 58 studies that met the eligibility criteria, only 21 papers were identified as strictly related to quality assurance and its perception by academic teachers and researchers. Most of them presented qualitative studies showing a negative attitude towards quality assurance.

\section{a) academics stances towards quality assurance systems}

The prevailing attitude of academics towards quality system is negative. External audits are perceived as "bureaucratic practice that has little impact on their work" (Cheng, 2010, p. 259), and quality assurance is seen as a form of implementing new public management, a form of discipline (Anderson, 2006; Lukas, 2014). Individuals are frustrated with "the neoliberal reforms in general, and assessment policies in particular" (Raaper, 2016, p. 175), and are struggling to understand the regulations. In addition, they are sometimes dissociating themselves from those practices and feel no ownership of the process. Academics do not reject the concept of quality assurance as such. The way it is shaped and implemented however is seen as incompatible with their work, concentrating on process rather than the content, and as a way to implement sanctions, leading to undesirable consequences such as academics' feeling the need to "play the game" (Vidovich and Porter, 1999, p. 574) and being tempted to "massage the figures" (Teelken, Lomas, 2009, p. 268). Nonetheless, the notion of quality as excellence is valued by academics. The one imposed by the quality assurance systems however, is either incompatible with it in any meaningful way or very vague (Mårtensson et al., 2012; Stamelos and Kavasakalis, 2011) and seen as "instrumental, minimalist, and mediocre" (Anderson, 2006, p. 171). Therefore all the quantitative measures that are required of academics are not leading to getting insight into quality (Anderson, 2006). "Quality" is seen as a way to discipline and control (Vidovich and Porter, 1999; Houston and Paewai, 2013), as well as a way to introduce fundamental changes in universities and lead to treating them as "simply another marketable commodity" (Alderman, 1996, p.184). Quality assurance is of no great interest and lacks academics involvement, which leads to high rates of suspending one's opinions concerning such systems. Self-assessment reports are often seen as not being a result of internal discussion and cooperation, and the final reports are not analysed critically (Veiga et al., 2013). As Bamber and Anderson (2012, p. 15) argue "evaluation which is rooted in academic practice within a specific discipline may be difficult to quantify, but it is just this type of evaluation which will lead to an enhancement. Evaluation which is focused on institutional performativity, on the other hand, may, at best, obtain little more than superficial compliance. At worst, it will be simply ignored". The label of "quality" is bestowed upon the university by external actors as if it was their property (Houston and Paewai, 2013). The academics are often excluded from narratives concerning quality policies and strategies (Smith, 2008), nor are they the real beneficiaries of the system as such. As Houston and Paewai (2013, p. 274) write: "only universities, academic units, academic staff and disciplines have the potential to use the information yielded by quality assurance to improve teaching, learning and research. However, the analysis shows that these groups are positioned as passive recipients of quality assurance system designs. The design and implementation of quality assurance occur at a distance from teaching, learning and research"(Houston and Paewai, 2013, p. 274).

Evaluations are seen as too frequent and overwhelming and therefore disrupting other activities such as teaching and research. They are sometimes seen as a waste of public money (Lucas, 2014; Veiga et al., 2013), ineffective, superficial and "measuring that which is measurable, and ignoring that which is useful" (Anderson 2006, p.168). The positive influence of quality assurance is not often noted by academics (Veiga et al., 2013; Wang, 2014) as it may be used against them as if it was a part of a power-knowledge regime. They are unable to contribute to quality improvements (Houston and Paewai, 2013) and are often de-coupled from academic life (Mårtensson, 2014). 
Lucas (2014, p. 218) analyses "incidents of resistance to the quality assurance processes relating to research and teaching in higher education in the UK" and shows that this opposition led to crucial changes within the polities and quality assurance practices in the UK. The author employs a Foucauldian framework devised by Hyatt (2013) with "modes of legitimation" including "authorisation, rationalisation and moral evaluation as three important concepts by which to investigate texts"(Lucas, 2014, p. 219). The two "critical cases" examined lead to the conclusion that

- the quality assurance methodology is not scientific, unable to influence the quality of teaching and research positively (rationale is questionable);

- needlessly increases the financial costs of the university and negatively influences the motivation to work since the continuous changes in quality assurance methodology undermine the possibility to measure changes across time (rationale is questionable);

- leads to such human costs as disorganisation of career development, working overtime with no financial compensation, sleepless nights, and disengages the individuals from the processes, limiting their actions to responses to external incentives (moral purpose is questionable).

Raaper (2016) argues that the frustration of academics may be connected with the changes in the aims of universities that are visible in every aspect of its functioning. Said changes entail losing control over such important aspect of their work as assessment: "academics feel as if they are tied to something that is used not only for educational purposes but also for wider neoliberal technologies of government such as auditing, monitoring and quality assurance mechanisms. It, therefore, appears as though (...) phrases that reflected confusion with assessment policies, and unhappiness with neoliberal reforms in higher education, reveal wider processes in relation to student assessment turning into a technology of government that functions as part of the neoliberal policy context and that increasingly scrutinises academics and their work for the sake of institutional market position" (Raaper, 2016, p. 182).

The 'atomization' and dissociation of academics in cases when quality assurance procedure is resulting in losing supervision over the curriculum is studied by Brady and Bates (2016). As the academics' role is switching from working together as a community negotiating the curriculum to alienated researchers appointed to deliver a given module, their attitude towards the curriculum and the organisation as a whole changes significantly. They feel as if they were a "cog in a wheel", "powerless, disconnected from the organisation or both" (Brady and Bates, 2016, p. 166).

Contrary to the finding presented above, the academics perception of quality assurance is positive in Finland and seen as a "means to administer their everyday life as long as academics' autonomy to their work is cherished and controlling mechanisms are avoided"(Husko and Ursin, 2017 , p. 868). One of the reasons may be that the Finnish system preserved the autonomy both on the university level and the fact that the "roots of the Finnish evaluation tradition lie on the idea of Humboldtian university" (Husko and Ursin, 2017, p. 867-868).

The findings summarized above represented the following countries: the United Kingdom, Portugal, China, Estonia, Finland, Greece, Spain, Vietnam, Australia, New Zealand. Only two papers presented comparative cross-country research: (the United Kingdom and the Netherlands, Hong Kong and Singapore). One paper did not specify in what country the research was performed.

\section{b) stances towards quality assurance systems: cross-country comparisons}

There are not many papers that compare the academics perception of quality assurance across at least two countries. Not many differences between countries have been identified. Teelken and Lomas (2009) argue that UK respondents connote quality assurance with quality control and are more inclined to a negative evaluation of the concept as such. Dutch respondents feel that their implicit 
norm of quality of research and teaching is not reflected in the current practices. They are also more explicit in looking for ways allowing them not to comply with the quality management system.

Quality assurance mechanisms introduced in Hong Kong and Singapore were designed to make the universities more competitive on a global education market and in fact, led to raising the position of their universities in the global ranking. Hong Kong academics found the research review process more intrusive and directive than the teaching one. On the one hand, a prevailing number of respondents evaluated research assessment as having some or a high impact ( $85 \%$ in Hong Kong and $97 \%$ in Singapore). On the other hand, the number of negative views was twice as much in Hong Kong. Regarding teaching assessment - twice as many positive views as negative ones were given in Hong Kong, and two-thirds of the views were positive in Singapore. The advantages of the assurance systems were connected with the belief that the quality system enhances research culture, quality and productivity in research and "the feedback is used constructively to improve (...) teaching" (Currie et al., 2008, p. 73). The negative ones were connected with the opinion that local and Chinese research is not likely to be published in top journals, as well as a high competitiveness and lack of trust in science. In addition, the "unreliability of the evaluations as some academics, lower their assessment standards to be more popular and hence achieve better student feedback".(Currie et al., 2008, p. 73). Currie et al. (2008, p. 83) conclude that "the greater the link to funding and compliance, the greater the possibility that academics will resent the intrusion, and a culture of mistrust rather than trust will begin to develop between them and the university of higher educational system managers, whether at the local, state or national level". Their findings show that the researchers are already more reluctant towards quality assurance than managers.

The positive correlation between the participation in quality assessment and the perception of the system as an improvement tool was found by Trullen and Rodríguez (2013). In addition, a negative correlation between the participation in such assessment and the perception of the system as an instrumental one (for example justifying budget cuts) was found. What is more, the perception of the system influences the level of identification with the program being assessed, as well as whether one is participating in the quality assessment. "Faculty who participate in quality assessments will be more likely to identify with the programme being assessed. Viewing quality assessments as motivated by improvement reasons will positively affect faculty identification with the programme being assessed and viewing quality assessments as motivated by instrumental reasons will negatively affect faculty identification with the programme being assessed" (Trullen and Rodríguez, 2013, p. 681-682).

\section{ACADEMIC VALUES}

Due to thematic focus on academic values a few papers were identified.

The longitudinal data analysis performed from the sixties to the nineties in Australian universities and colleges concerning how the academics perceive their roles reveal that they value: "the freedom to do original work; a flexible work schedule; independence and autonomy; the opportunity to make a contribution to knowledge; the social aspects of the job; the salary; and prestige associated with being an academic" (Adams, 1998, p. 427).

The author claims that the factors that may undercut academics motivation and job satisfaction are an erosion of that core values and satisfaction of academic work caused by legislation or regulation. If what is considered "a marginal work" such as additional activities besides research and teaching will be growing, it may affect the essential values and expectations of academic culture (Adams, 1998).

Other authors see referring to values while explaining academics reluctance to accept some policies as "simplistic explanations attributing lack of adherence to ideas of academic freedom (...) 
[which] cover up a lack of research-based understandings of why academics act as they do" (Brew et al., 2017, p. 379).

They argue that the diversity of academics' responses to university policies and strategic initiatives may be interpreted and understood partially at least by using the Archer's (2007) modes of reflexivity. Those responses were interpreted within the framework of those modes, mediated by career aspirations. In addition, one's perception of what is desirable enables us to understand why policies sometimes fail, and do not lead to the desired outcomes. For instance, on the one hand, the meta-reflexivity mode which is "characterised by internal conversations critical of one's internal conversations and on the look-out for a difference in the social world around them" (Brew et al., 2017, p. 380) is the crucial one when implementing a new policy and most helpful for the organisation. On the other hand, academics exhibiting traces of fractured-reflexivity ("internal conversations intensify distress and disorientation rather than leading to purposeful courses of action") need professional help in accepting changes (Brew et al., 2017, p. 380). Therefore, it is the organisation's responsibility to address the personal model of reflexivity of an academic and adjust the message concerning the new requirements to it.

Parker (2011, p. 440) provides a list of focal values that the university is expected to fulfil nowadays:

- "knowledge as a driver of national economic development;

- universities services and products as key national export commodities;

- the primacy of knowledge for industry application;

- employable graduate output;

- operational values for money, efficiency, and effectiveness;

- fee-for-service and market competitive deliverables".

Those values are enforced onto universities and become another level of tension between what is expected by academics and what is expected by the governments, society and top-decision makers at universities. That entails the profound changes in the perception of a role of an academic, the "unique roles of an independent, professional, expert educators and research scholars operating in collegial association and co-decision-making with the university in which they were members"(Parker 2011, p. 444). This is being gradually replaced by defining them as "teaching, research and administrative employees in the university, subject to its strategic objectives and direction, and driven and evaluated by corporate KPIs that drill down from university to faculty, to school, to individual levels." (Parker 2011, p. 444).

\section{UNIVERSITY GOVERNANCE}

Twenty-five papers concerning university governance have been identified on the basis of their thematic focus. . Their main topics are the shifts in power balance and academic autonomy due to managerialism at universities (Bleiklie and Kogan, 2007; Carvalho and Videira, 2017; Giroux et al., 2015; Kolsaker, 2008; Parker, 2011; Salter and Tapper, 2000; Taylor 2013), as well as the decline in academic participation in governance (Dowling-Hetherington, 2013; Lapworth, 2004; Shattock, 2002; Shattock, 2013; Vidovich and Curie, 2010). Quality assurance as an example of a practice that plays a role in that transformation undermining traditional academic values is frequently listed or discussed in more details (Bleiklie and Kogan, 2007; Salter and Tapper, 2000; Azman et at., 2012).

\section{a) The interplay of autonomy, mistrust and modes of governance}

The shift from the classic notion of the university seen as a republic of scholars towards the university perceived as a stakeholder organisation is analysed by Bleiklie and Kogan (2007). The difference between them is mainly concentrated around the way the institutional autonomy and 
academic freedom are considered. The first notion entails that institutional autonomy and academic freedom are interlinked - "which means that leadership and decision making are based on collegial decisions made by independent scholars" (Bleiklie and Kogan, 2007, p. 477). Traditionally, the collegial approach lies at the core and central place in the decision-making process and is a value "underpinning academic life" (Dowling-Hetherington, 2013, p.220). The fact that the faculty's influence on the decision-making process is decreasing is very often regarded as a disillusionment (Dowling-Hetherington, 2013). The second notion treats academic freedom as a voice of one of the many stakeholders whose interest the decision makers are to protect. The authors argue, that "a powerful force lending support to the growth of managerialism has been the assertion of quite penetrative quality assurance procedures that replace the hitherto 'trustful' relationships between academics and their institutions as they believe in 'transparency' has replaced the trust in expert and professional knowledge"(Bleiklie and Kogan, 2007, p. 480).

However, the implementation of quality assurance systems (as an element of managerialism) does not necessarily entail excluding scholars' autonomy, as "the general ideological pressure in individual countries is mediated through specific national policies based on experiences and issues that constitute powerful political, legal and financial operating conditions" (Bleiklie and Kogan, 2007, p. 480). Therefore, the relations between the four principles: professional self-regulation, sensitive democracy, bureaucratic steering, and corporate management specify the organisational ideas and lead to varying across "time and across institutions and educational systems" (Bleiklie and Kogan, 2007, p. 485).

Shattock (2013) explains the arrival of quality assurance officers in terms of filling the void after the decline of academics participation in governance, and states that "university governance and management are falling into the hands of 'management teams' that are less and less either accountable to, or working in partnership with, the rest of the components of the institution" (Shattock, 2013, p. 230). This is also an argument raised by Vidovich and Curie (2010) as a result of their analysis of the Australian and UK national governance policy that lead them to the conclusion that the recent development in said area increases mistrust across the sector. Some of the solutions proposed are a flexible model of governance (Lapworth, 2004), promoting academics participation in areas in which they "have better information and incentives than administrators of trustees" (Brown, 2001, p. 130), as well as a model of shared governance (Taylor, 2013) "reframing faculty senates-in-practice from political to collaborative entities" in order to break " the competitive stalemate" (Gallos, 2009, p. 137).

A typology of three ideal types of universities (the state-centered model, market-oriented model, and academic self-governance) with empirically observable indicators is presented to enable "trace and operationalise the extent and direction of policy change or persistence in European higher education systems." (Dobbins et al., 2011, p. 679). In addition, in other papers the proposals for changes are to be found. Shattock argues that "shared governance" emerging in the USA is the most advantageous model of university governance while "the corporate model is no more desirable or effective in modern conditions than the consensual model implied by academic dominance of the governing process" (Shattock, 2002, p. 236). Trakman (2008), on the other hand, argues against "a one-size-fits-all-model" and identifies and evaluates "five primary models of board-level governance in universities: (1) faculty; (2) corporate; (3) trustee governance; (4) stakeholder; and (5) amalgam models of governance." (Trakman, 2008, p. 63).

Parker (2011) argues that the new mode of university governance that is replacing the collegial, consultative model is a rebirth of scientific management from a century ago with its promotion of a centralised style of governance. 


\section{b) Quality assurance systems impact on performance and behaviour}

The "issues of behavioural consequences of quantitative performance measurement in universities" is studied by Frost and Brockmann (2014, p. 27). They argue that while the implementation of performance indicators increased the academic research output, it also brought dysfunctional effects and thus led to "a performance paradox" (Frost and Brockmann, 2014, p. 27). The causal patterns of that paradox are "inaccurate reports on scholars' performances; lack of congruence between political goals and performance indicators in use; de-contextualization of knowledge; ambiguity and myopia" (Frost and Brockmann, 2014, p. 33). They lead to such behaviours and actions as gaming, pigeonholing, cherry-picking, salami-slicing, measure fixation and publication inflation. In the long run, the creativity, innovativeness and progress in science are impeded and scientific curiosity suppressed by adopting the strategy of playing safe. Franco-Santos et al. (2017) concludes that "current transition towards enhanced control governance with increasing reliance on hard performance measures and targets for academics may lead to dysfunctionalities rather than the intended improvements"(Franco-Santos et al., 2017, p. 724).

A typology of a regulator as an ally, threat and obstacle was proposed by Gray and Silbey (2014). The goal of said article was to provide a framework for understanding the response of actors within the organisation to the new university requirements.

Maassen searches for an explanation of the university's governance paradox - "the more university leaders take on and operate in line with the reform agenda's underlying ideologies, the less effective they appear to be in realising the reform intentions". (Maassen, 2017, p. 290). He argues that the reforms treat universities as if they were of the same substance as other organisations, especially business ones, to which incentives build upon economic reasoning and financial effectiveness should appeal. However, universities' integral and indispensable goal is prestige maximisation, which is gained by academics publishing in top journals, gaining grants and scientific prizes. The success rate of said activities and outcomes can never be predicted beforehand and is easily governed directly by leadership. It is the autonomy and flexibility of academics which needs to be preserved in order to create an appropriate environment for researchers. Too direct and perceptible control will probably hinder researchers and discourage them from searching employment in such universities (Maassen, 2017). Autonomy, creativity and an unstable environment are characteristics for lowstructured roles such as researchers and general knowledge workers (Franco-Santos et al., 2017). Collegial governance is positively related to the well-being and low-stress levels of academics not having leadership responsibilities, while high-level control governance is leading to a high level of stress for that group. However, the relation between the type of governance and welfare of staff is different for non-academic employees and scholars having leadership responsibilities. The first group prefers control governance, and the latter feels well in both types of governance. The reason may be that the non-academic staff has already experienced business-like job arrangements and hasn't been acquainted with other possibilities, and "when academics ascend to leadership positions, it appears that the needs and expectations of the role position change their outlook and sentiment towards governance"(Franco-Santos et al., 2017, p. 724).

The frictions between professors and university governance at a German university have been investigated by Lueg (2018) as well. Their response to strategy papers concerning Europeanization was mostly negative. They considered it a superfluous initiative and were detached form university governance. A smaller group of professors possessed a more critically-supportive stance. What is more, the governance-detached professors claimed their actions are in no way affected by this strategic initiative, and that they were promoting said attitude among junior staff as well. Therefore, their stance was undermining the leadership, which, surprisingly, sometimes justified the resistance of professors. To sum up, "both narrative and counter-narrative find legitimacy, and thereby impede 
organisational change" and "this has implications for how positioning and power are understood in a university facing a change process: organisational and counter-narrative cannot be considered pure dichotomies" (Lueg, 2018, p. 15).

Kolsaker (2008) argues that despite the very negative and pessimistic accounts of the impact of managerialism on scholars, they are rather positive and pragmatic about the changes. She employs a Foucauldian epistemology to study their attitude and concludes that power has not been taken away from them, as well as that academics are in no retreat, but instead that "managerialism has simply changed the ways in which power is exercised in English universities today". (Kolsaker, 2008, p. 516).

The reform of higher education institutions in Singapore and Malaysia carried out in the name of corporatisation did not lead to a transformation of university management but raised the level of pressure the scholars' experience (Mok, 2008). A comparative study of nine universities from Australia, the UK, Belgium, the Netherlands and Malaysia provides insight into the factors and the various levels of their influence in each of the countries on universities. The five influencing forces are

- the government sector;

- the state government/other funding bodies/local industry/local councils;

- global competitions;

- collegial managerialism, autonomy and academic culture;

- and internal management.

The conclusion concerning the fourth factor is that any governance system should embrace the "collegial and autonomous culture" in the case of all universities studied except the Malaysian one, in which the level of control is very high and "collegiality and academic freedom are either nonexistent or within the confines of this control" (Christopher, 2012, p. 345).

An impact of "national and institutional features of governance and management" on quality assurance policies, procedures and actual improvement was studied by Sarrico et al. (2013, p. 375) in four Portuguese universities and polytechnic institutions. The real impact of the system is rather questionable, but still, the system is perceived as a necessity. It is to some extent accepted that lecturers are under the pressure of gathering data, building information systems, as well as allocating some of their time to growing managerial and administrative tasks by deducing that time from research and teaching. This however also leads to perceiving quality as "producing measure and reports, and people are conscious that nothing will essentially change because of that". (Sarrico et al., 2013, p. 386).

\section{INSTITUTIONAL LOGICS}

The conflict of logics in various areas of higher education is investigated in 11 papers. However, none of them explores whether quality assurance is an arena of plural institutional logics conflict or coexistence. Institutional logics are discussed in the context of university management, leadership (Howells et al., 2014), and governance (Blaschke et al., 2014); medical profession (Dunn and Jones, 2010); R\&D collaboration between universities and industry (Bjerregaard (2010); market logic entering the university realm (Bjerregaard, 2010; Berman, 2012); excellence treated as a part of institutional logics and institutional myth (O'Connor and O'Hagan, 2016); “ideal" models of institutional logics aligned with Triple Helix activities (Cai, 2015); defensive mechanism concerning responding to stakeholders' critique of university (Mampaey and Huisman,2016); identifying values and multiple logics in Chinese doctoral education system (Zheng et at., 2018); and academics coping mechanisms for competing logics of science and business (David et al., 2018, p. 386). 
Blaschke et al., (2014) explores the relation between governance, leadership and managerialism as not necessary in conflict, but coexisting and corresponding due to complementary sequences of micro patterns such as agenda building, critical reflection and debriefing with one of the micro patterns - devising being attributed to management and government only. The authors argue that the core activities of a university, research and science, are decoupled from managerialism: "despite the shift towards business-like leadership and management styles in universities, the academic authority over teaching and research largely prevails". (Blaschke et al., 2014, p. 726).

A cross-case analysis of mission statements of three universities in the USA provided an insight into the relation of 'industry' logics (referenced to "market forces, economic development and workforce skills"; Upton et al., 2017, p. 98) and 'social institution' logic' ("which draws legitimacy from social goals as well as 'traditional academic ideals"”; Upton et al., 2017, p. 98). According to these findings, those logics generally coexist and are mutually dependent. Only in some areas (such as student recruitment) are they apt to lead to tensions or conflicts. According to Upton et al. (2017), the analyzed mission cannot be fully understood without employing two of the logics simultaneously. Therefore the conclusion is that they are no longer two truly separate logics, but one hybridized one.

Dunn and Jones (2010) discuss two logics (care and science) that are central to the medical profession "supported by distinct groups and interest, fluctuate over time, and create dynamic tensions about how to educate future professionals" (Dunn and Jones, 2010, p. 114). The paper examines reasons why professions may be prone to be "the subject of multiple logics". It also gives arguments for why such a plurality may regulate conflicts if the logics stay in balance, as well as identifies "shifts in the attention to and emphasis on particular logics in a profession." (Dunn and Jones, 2010, p. 114).

The impact of changing institutional logics on R\&D collaboration between universities and the industry resulting in adapting scientific values by firms and entrepreneurial ones by the university has been explored by Bjerregaard (2010). Berman (2012) proposed a model for explaining how the environmental changes may encourage the growth of impact of a logic that is not a dominant one. Howells et al. (2014) discusses what leadership skills should be employed in times of paradigm shifts and plural institutional logics.

A concept of excellence crucial for the evaluation of university faculty is being analysed by O'Connor and O'Hagan (2016). The findings unfold that excellence that is not as gender-neutral and objective notion as is often assumed to be. Therefore the credibility of it and the legitimacy of an organisation that is built upon that notion are questioned (O'Connor and O'Hagan, 2016).

Relations between stakeholders and the university in terms of responding to the stakeholders' critique are analyzed by Mampaey and Huisman (2016) to propose that "in HEIs where a particular logic is salient, conflict-reducing strategies will be deployed in response to stakeholders who criticize that logic whereas conflict-inducing strategies will be deployed in situations where other logics are criticized"(Mampaey and Huisman, 2016, p. 2227). They argue that it is not uncommon, however not often researched, that the university may choose to deny responding to a critique in order not to acknowledge it. It also explains why universities are not keen on building a strong relationship with stakeholders if both sides do not share the same values and institutional logic.

\section{CONCLUSIONS}

This article has explored the changes that the introduction of quality assurance - one of the manifestations of university corporatisation and neo liberal ideology - brought to HEIs and its impact on academics. 
As the concept of quality assurance is as such not refuted by scholars, its implementation, procedures and actions that the system entails are seen as having a "hidden agenda" in the background - serving not the university and its scholars, but external stakeholders. Its true essence is believed to be of disciplining nature, with little or no impact on improvements in terms of quality of teaching or research, but with high costs on academics' time, motivation and career development. The methodology of the system is sometimes seen as not scientific, overwhelmingly bureaucratic and not compatible with the role of an academic for whom the core activities are research and teaching. The system as such is of no interest for most scholars.

The revision of traditional values, power balance, academic freedom and autonomy perceived by academics is frequently regarded as a disillusionment and a threat of losing the most core underpinnings of academic life. Quality assurance is seen as a game that one needs to play. The attitude of lack of ownership of the process is occurring, as well as the belief that the system actually does not entail many improvements but is a source of control and discipline. In the light of the current changes, the academics are reported as declining in participation in governance, and the void is being replaced by quality assurance officers that lead the university even further towards corporatisation. The ideas of accountability, values for money and transparency are paradoxically resulting in an outgrowth of mistrust, tension, raising the level of pressure on academics and developing various coping strategies such as decoupling or mimetic isomorphism (Blaschke et al., 2014; Parker, 2011; Lueg, 2018).

The traditional role of an academic for whom research and teaching are the essential activities is being undermined by the necessity of assigning time for time-consuming administrative and managerial tasks with no concrete payoffs.

Research shows that role conflict, and role ambiguity are dysfunctional factors influencing one's effectiveness and job satisfaction (Rizzo et al., 1970) and although sometimes inevitable should be minimised (Floyd and Lane, 2000). What is more, it's the administrative part of the job, and the awareness of being controlled that tend to be the most negative job experience, as Williams et al., (1991) claims. The generally unfavourable perception of the quality system could also be interpreted in terms of those findings.

Another possible contribution to the previous research could be investigating if research on quality assurance is an area prone to interest conflicts, and if so, to what extent and how to ensure maintaining a neutral stand.

Nonetheless, the question can be asked whether the overly negative perception of quality assurance linking the system to restraining academic freedom and autonomy is inevitable. As Bleiklie and Kogan (2007) point out, "the general ideological pressure in individual countries is mediated through specific national policies" (Bleiklie and Kogan, 2007, p. 458) and do not have to entail diminishing academic autonomy. There are, however, not many comparative studies across various countries to investigate that. Another question is whether the prevailing attitudes will be preserved, or whether the interplay of managerialism and traditional view of a university will lead to some kind of a merge in the long run. Are decoupling, gaming, questionable research practices and other coping strategies to become an irremovable part of the picture, or just a temporary solution? There is a need for longitudinal research in that field in order to establish that. Is the case of quality assurance perception an arena on which two institutional logics collide? This remains to be unknown since no papers exploring that approach have been identified in this SLR.

Upton et al. (2017) state that not much attention so far has been given to conceptualise and analyse institutional logics at the university level, as well as that "the complexity of relationships among multiple logics remains less well understood than the ascendancy of one over the other" (Upton et al. 2017, p. 90). The authors also argue that "the concept of hybrid or blended logics suggests a promising framework for understanding how universities can and do manage and exploit tensions in 
their missions" Upton et al. 2017, p. 100). and that if "appropriately applied, the findings could serve as another tool in universities' multifaceted response to institutional complexity" (Upton et al. 2017, p. 101). Upon the conducted research, it may be stated that using the institutional logics analytical framework for analysing quality assurance perception and efficiency in bringing improvements to universities is a research gap. It however also showcases as a promising area of contributing insight to "universities' multifaceted response to institutional complexity" (Upton, 2017, p. 101).

In terms of analytical methods used in the selected papers, it is worth noticing, that most of the research was based on qualitative methods and small sample sizes (between 20-50 interviewees). A quantitative approach and significantly bigger sample sizes were used only eight times including three papers with a mixed approach. For that reason, the recommendation to employ quantitative methods more frequently is concluding the list of research gaps identified in this paper.

\section{LIMITATIONS}

The systematic literature review presented here has its limitations. One of it is restraining the search to one database only. Another one is that it could be useful to add managerialism or new public management to the search words to receive a broader set of papers. The results of the papers' analysis show that the list of identified papers should be treated as a starting point for additional research since the chosen keywords did not identify a lot of valuable papers. All generalisations presented in the papers should be accepted with care, as the conclusions of papers presented were mostly drawn on qualitative studies, small sample sizes and studies bound to the specific culture and organisations.

The paper presents the perception of quality systems of one stakeholders only; therefore, to broaden the perspective the analysis of other stakeholders should follow in further research. Including their view could enable to give answers to such question how does the perception of quality assurance systems differ among various groups of stakeholders.

\section{Literature}

Adams, D. (1998). Examining the fabric of academic life: An analysis of three decades of research on the perceptions of Australian academics about their roles. Higher Education, 36(4), 421-435. https://doi. org/10.1023/A:1003423628962

Ala-Vähälä, T. (2016). Reception of the quality assurance commitments of the Bologna process in Finnish higher education institutions. Quality in Higher Education, 22(2), 103-116. https://doi.org/10.1080/13538 322.2016.1195966

Alderman, G. (1996). Audit, assessment and academic autonomy. Higher Education Quarterly, 50(3), 178-192. https://doi.org/10.1111/j.1468-2273.1996.tb01700.x

Anderson, G. (2006). Assuring quality/resisting quality assurance: Academics' responses to 'quality' in some Australian universities. Quality in Higher Education, 12(2), 161-173. https://doi.org/10.1080/13538320600916767

Archer, M.S. (2007). Making our way through the world: Human reflexivity and social mobility. Cambridge: Cambridge University Press.

Azman, N. (2012). Malaysian public universities governance system: A compromise between collegiality, autonomy and corporate management approaches. International Journal of Knowledge, Culture and Change Management, 11(5), 115-133.

Bamber, V., Anderson, S. (2012). Evaluating learning and teaching: Institutional needs and individual practices. International Journal for Academic Development, 17(1), 5-18. https://doi.org/10.1080/1360144X.2011.586459

Berg, C. (1993). University autonomy and quality assurance. Higher Education in Europe, 18(3), 18-26. https:// doi.org/10.1080/0379772930180303

Berman, E.P. (2012). Explaining the move toward the market in US academic science: How institutional logics can change without institutional entrepreneurs. Theory and Society, 41(3), 261-299. https://doi.org/10.1007/ s11186-012-9167-7 
Bjerregaard, T. (2010). Industry and academia in convergence: Micro-institutional dimensions of R\&D collaboration. Technovation, 30(2), 100-108. https://doi.org/10.1016/j.technovation.2009.11.002

Blaschke, S., Frost, J., Hattke, F. (2014). Towards a micro foundation of leadership, governance, and management in universities. Higher Education, 68(5), 711-732. https://doi.org/10.1007/s10734-014-9740-2

Bleiklie, I., Kogan, M. (2007). Organization and governance of universities. Higher Education Policy, 20(4), 477-493. https://doi.org/10.1057/palgrave.hep.8300167

Brady, N., Bates, A. (2016). The standards paradox: How quality assurance regimes can subvert teaching and learning in higher education. European Educational Research Journal, 15(2), 155-174. https://doi. org $/ 10.1177 / 1474904115617484$

Brew A., Boud D., Lucas L., Crawford K. (2017). Responding to university policies and initiatives: the role of reflexivity in the mid-career academic. Journal of Higher Education Policy and Management, 39(40), 378-389. https://doi.org/10.1080/1360080X.2017.1330819

Briner R. B., Denyer D. (2012). Systematic Review and Evidence Synthesis as a Practice and Scholarship Tool. In D. M. Rousseau (Ed.), Oxford Handbook of Evidence-Based Management: Companies, Classrooms and Research (pp. 112-129), Oxford University Press. https://doi.org/10.1093/oxfordhb/9780199763986.013.0007

Brown Jr., W. O. (2001). Faculty participation in university governance and the effects on university performance. Journal of Economic Behavior and Organization, 44(2), 129-143.

Cai, Y. (2015). What contextual factors shape 'innovation in innovation'? Integration of insights from the Triple Helix and the institutional logics perspective. Social Science Information, 54(3), 299-326. https:// doi.org/10.1177/0539018415583527

Carvalho, T., Videira, P. (2017). Losing autonomy? Restructuring higher education institutions governance and relations between teaching and non-teaching staff. Studies in Higher Education, 44(4), 762-773. https://doi. org/10.1080/03075079.2017.1401059

Cheng, M. (2010). Audit cultures and quality assurance mechanisms in England: A study of their perceived impact on the work of academics. Teaching in Higher Education, 15(3), 259-271. 10.1080/13562511003740817

Christopher, J., (2012). Governance Paradigms of Public Universities: An international comparative study. Tertiary Education and Management, 18(4), 335-351. https://dx.doi.org/10.1080/13583883.2012.724705

Currie, J., Vidovich, L., Yang, R. (2008). Countability not answerability? Accountability in Hong Kong and Singapore universities. Asia Pacific Journal of Education, 28(1), 67-85. https://doi.org/10.1080/02188790701845972

David, F., van der Sijde, P., van den Besselaar, P. (2018). Academics coping with business logic: A study at Indonesian universities. Journal of Engineering and Technology Management - JET-M, 48, 91-108, doi. org.10.1016/j.engtecman.2018.07.002

Dobbins, M., Knill, C., Vögtle, E. M. (2011). An analytical framework for the cross-country comparison of higher education governance. Higher Education, 62(5), 665-683. https://doi.org/10.1007/s10734-011-9412-4

Dowling-Hetherington, L. (2013). The Changing Shape of University Decision-Making Processes and the Consequences for Faculty Participation in Ireland. Tertiary Education and Management, 19(3), 219-232. https:// doi.org/10.1080/13583883.2013.790071

Dunn, M. B., Jones, C. (2010). Institutional logics and institutional pluralism: The contestation of care and science logics in medical education, 1967-2005. Administrative Science Quarterly, 55(1), 114-149. https:// doi.org/10.2189/asqu.2010.55.1.114

Floyd, S.W., Lane, P.J. (2000). Strategizing throughout the Organization: Managing Role Conflict in Strategic Renewal. The Academy of Management Review, 25(1), 154-177. https://doi.org/10.2307/259268

Franco-Santos, M., Nalick, M., Rivera-Torres, P., Gomez-Mejia, L. (2017). Governance and Well-being in Academia: Negative Consequences of Applying an Agency Theory Logic in Higher Education. British Journal of Management, 28(4), 711-730. https://doi.org/10.1111/1467-8551.12249

Frost, J., Brockmann, J. (2014). When qualitative productivity is equated with quantitative productivity: scholars caught in a performance paradox [Wenn Qualität von Forschung, Lehre und Bildung mit quantitativer Produktivität gleichgesetzt wird - im Leistungsparadoxon gefangene Wissenschaftler]. Zeitschrift fur Erziehungswissenschaft, 17(6), 25-45.

https://doi.org/10.1007/s11618-014-0572-8

Gallos, J. V. (2009). Reframing shared governance: Rediscovering the soul of campus collaboration. Journal of Management Inquiry, 18(2), 136-138. https://doi.org/10.1177/1056492608326326

Giroux, D., Karmis, D., Rouillard, C. (2015). Between the managerial and the democratic university: Governance structure and academic freedom as sites of political struggle. Studies in Social Justice, 9(2), https:// doi.org/142-158. 10.26522/ssj.v9i2.1149

Gray, G. C., Silbey, S. S. (2014). Governing inside the organization: Interpreting regulation and compliance. American Journal of Sociology, 120(1), 96-145. 
Houston, D., Paewai, S. (2013). Knowledge, power and meanings shaping quality assurance in higher education: A systemic critique. Quality in Higher Education, 19(3), 261-282. https://doi.org/10.1080/13538322 .2013 .849786

Howells, J.R.L., Karataş-Özkan, M., Yavuz, Ç., Atiq, M. (2014). University management and organisational change: A dynamic institutional perspective. Cambridge Journal of Regions, Economy and Society, 7(2), 251-270. https://doi.org/10.1093/cjres/rsu005

Huusko, M., Ursin, J. (2010). Why (not) assess? Views from the academic departments of Finnish Universities. Assessment and Evaluation in Higher Education, 35(7), 859-869. https://doi.org/10.1080/02602930903125264

Hyatt, D. (2013). The critical policy discourse analysis frame: Helping doctoral students engage with the educational policy analysis. Teaching in Higher Education, 18(8), 833-845. https://doi.org/10.1080/1356 2517.2013 .795935

Kolsaker, A. (2008). Academic professionalism in the managerialist era: A study of English universities. Studies in Higher Education, 33(5), 513-525. https://doi.org/10.1080/03075070802372885

Lapworth, S. (2004). Arresting decline in shared governance: Towards a flexible model for academic participation. Higher Education Quarterly, 58(4), 299-314. https://doi.org/10.1111/j.1468-2273.2004.00275.x

Lucas, L. (2014). Academic resistance to quality assurance processes in higher education in the UK. Policy and Society, 33(3), 215-224. https://doi.org/10.1016/j.polsoc.2014.09.006

Lueg, K. (2018). Organizational changes towards a European academic field. A case study of frictions in the narratives of Europeanization at a German university from an institutional perspective. Innovation, 31, 454-503, https://doi.org/10.1080/13511610.2018.1490637

Maassen, P., (2017). The university's governance paradox. Higher Education Quarterly, 71(3), 290-298. https:// doi.org/10.1111/hequ.12125

Mampaey, J., Huisman, J. (2016). Defensive stakeholder management in European universities: an institutional logics perspective. Studies in Higher Education, 41(12), 2218-2231. https://doi.org/10.1080/03075079.201 5.1029904

Mårtensson, K., Roxå, T., Stensaker, B. (2014). From quality assurance to quality practices: an investigation of strong microcultures in teaching and learning. Studies in Higher Education, 39(4), 534-545. https://doi. org/10.1080/03075079.2012.709493

Mok, K. H. (2008). Singapore's global education hub ambitions: University governance change and transnational higher Education. International Journal of Educational Management, 22(6), 527-546. https://doi. org/10.1108/09513540810895444

O’Connor, P., O’Hagan, C. (2016). Excellence in university academic staff evaluation: a problematic reality? Studies in Higher Education, 41(11), 1943-1957. https://doi.org/10.1080/03075079.2014.1000292

Ordorika, I. (2014). Governance and change in higher education: The debate between classical political sociology, new institutionalism and critical theories. Bordon, 66(1), 107- https://doi.org/10.13042/Bordon.2014.66107

Parker, L. (2011). University corporatisation: Driving redefinition. Critical Perspectives on Accounting, 22(4), 434-450. https://doi.org/10.1016/j.cpa.2010.11.002

Raaper, R. (2016). Academic perceptions of higher education assessment processes in neoliberal academia. Critical Studies in Education, 57(2), 175-190. https://doi.org/10.1080/17508487.2015.1019901

Rizzo, J.R., House, R.J., Lirtzman, S.I. (1970). Role Conflict and Ambiguity in Complex Organizations. Administrative Science Quarterly, 15(2), 150-163. http://dx.doi.org/10.2307/2391486

Salter, B., Tapper, T. (2000) The politics of governance in higher education: The case of quality assurance. Political Studies, 48(1), 66-87. https://doi.org/10.1111/1467-9248.00251

Sarrico, C.S., Veiga, A., Amaral, A. (2013). The long road-how evolving institutional governance mechanisms are changing the face of quality in Portuguese higher education. Educational Assessment, Evaluation and Accountability, 25(4), 375-391. https://doi.org/10.1007/s11092-013-9174-X

Shattock, M. (2002). Re-balancing modern concepts of university governance. Higher Education Quarterly, 56(3), 235-244. https://doi.org/10.1111/1468-2273.00215

Shattock, M., (2006). Managing Good Governance in Higher Education. Maidenhead: OpenUniversity Press.

Shattock, M. (2013). University governance, leadership and management in a decade of diversification and uncertainty. Higher Education Quarterly, 67(3), 217-233. https://doi.org/10.1111/hequ.12017

Smith, K. (2008). 'Who do you think you're talking to?' - The discourse of learning and teaching strategies. Higher Education, 56(4), 395-406. https://doi.org/10.1007/s10734-007-9100-6

Stamelos, G., Kavasakalis, A. (2011). The public debate on a quality assurance system for Greek universities. Quality in Higher Education, 17(3), 353-368. https://doi.org/10.1080/13538322.2011.628807

Steinhardt, I., Schneijderberg, C., Götze, N., Baumann, J., Krücken, G. (2017). Mapping the quality assurance of teaching and learning in higher education: the emergence of a specialty? Higher Education, 74(2), 221-237. https://doi.org/10.1007/s10734-016-0045-5 
Stensaker, B. (2007). Quality as fashion: Exploring the translation of a management idea into higher education. In M. J. Rosa, B. Stensaker, \& D. F. Westerheijden (Eds.), Quality assurance in higher education trends in regulation, translation and transformation (pp. 99-118). Dordrecht, Netherlands: Springer. https://doi. org/10.1007/978-1-4020-6012-0_4

Taylor, M. (2013). Shared Governance in the Modern University. Higher Education Quarterly, 67(1), 80-94. https://doi.org/10.1111/hequ.12003

Teelken, C., Lomas, C., L. (2009). How to strike the right balance between quality assurance and quality control in the perceptions of individual lecturers": A comparison of UK and Dutch higher education institutions. Tertiary Education and Management, 15(3), 259-275. https://doi.org/10.1080/13583880903073016

Trakman, L. (2008). Modelling university governance. Higher Education Quarterly, 62(1-2), 63-83. https://doi. org/10.1111/j.1468-2273.2008.00384.x

Trullen, J., Rodríguez, S. (2013). Faculty perceptions of instrumental and improvement reasons behind quality assessments in higher education: the roles of participation and identification. Studies in Higher Education, 38(5), 678-692. https://doi.org/10.1080/03075079.2011.590587

Upton, S., Warshaw, J. B., (2017). Evidence of hybrid institutional logics in the US public research university. Journal of Higher Education Policy and Management, 39(1), 89-103. https://doi.org/10.1080/136008 0X.2017.1254380

Veiga, A., Rosa, M. J., Dias, D., Amaral, A. (2013). Why is it difficult to grasp the impacts of the Portuguese quality assurance system? European Journal of Education, 48(3), 454-470. https://doi.org/10.1111/ejed.12040

Vidovich, L., Currie, J. (2011). Governance and trust in higher education. Studies in Higher Education, 36(1), 43-56. https://doi.org/10.1080/03075070903469580

Vidovich, L., Porter, P. (1999). Quality policy in Australian higher education of the 1990s: University perspectives. Journal of Education Policy, 14(6), 567-586. https://doi.org/10.1080/026809399286099

Wang, L. (2014). Quality assurance in higher education in China: Control, accountability and freedom. Policy and Society, 33 (3), 253-262. https://doi.org/10.1023/A:1014616110418

Williams, K. J, Suls, J., Alliger G. M., Learner, S. M., Wan C. K. (1991). Multiple role juggling and daily mood states in working mothers: an experience sampling study. Journal of Applied Psychology, 76(5), 664-74. http://dx.doi.org/10.1037/0021-9010.76.5.664

Zheng, G., Shen, W., Cai, Y. (2018). Institutional logics of Chinese doctoral education system. Higher Education, 76(1), 753-770, https://doi.org/10.1007/s10734-018-0236-3 


\section{APPENDIX}

List of journals and number of papers included in the SLR

\begin{tabular}{|c|c|}
\hline Journal & Number of papers \\
\hline Higher Education Quarterly & 7 \\
\hline Studies in Higher Education & 5 \\
\hline Higher Education & 4 \\
\hline Quality in Higher Education & 3 \\
\hline Studies in Higher Education & 2 \\
\hline Journal of Higher Education Policy and Management & 2 \\
\hline Policy and Society & 2 \\
\hline Asia Pacific Journal of Education & 1 \\
\hline Critical Studies in Education & 1 \\
\hline Economy and Society & 1 \\
\hline European Educational Research Journal & 1 \\
\hline Higher Education & 1 \\
\hline Innovation & 1 \\
\hline International Journal of Educational Management & 1 \\
\hline Journal of Engineering and Technology Management - JET-M & 1 \\
\hline Tertiary Education and Management & 1 \\
\hline Administrative Science Quarterly & 1 \\
\hline American Journal of Sociology, & 1 \\
\hline Assessment and Evaluation in Higher Education & 1 \\
\hline British Journal of Management & 1 \\
\hline Critical Perspectives on Accounting & 1 \\
\hline Educational Assessment, Evaluation and Accountability & 1 \\
\hline European Journal of Education & 1 \\
\hline Higher Education in Europe & 1 \\
\hline Higher Education Policy & 1 \\
\hline International Journal for Academic Development & 1 \\
\hline International Journal of Knowledge, Culture and Change Management & 1 \\
\hline Journal of Economic Behavior and Organization & 1 \\
\hline Journal of Education Policy & 1 \\
\hline Journal of Management Inquiry & 1 \\
\hline Political Studies & 1 \\
\hline Quality in Higher Education, & 1 \\
\hline Social Science Information & 1 \\
\hline Studies in Social Justice, & 1 \\
\hline Teaching in Higher Education & 1 \\
\hline Technovation & 1 \\
\hline Tertiary Education and Management & 2 \\
\hline Theory and Society & 1 \\
\hline Zeitschrift fur Erziehungswissenschaft & 1 \\
\hline Total & 58 \\
\hline
\end{tabular}

